\title{
Estimation of Natural Gas Demand in Industry Sector of Iran: A Nonlinear Approach
}

\author{
Alireza H. Kani ${ }^{1}$, Majid Abbaspour ${ }^{1,2}$ \& Zahra Abedi ${ }^{3}$ \\ ${ }^{1}$ Energy Engineering Dep., Faculty of Environment and Energy, Scienece and Research Branch, Islamic Azad \\ University, Tehran, Iran \\ ${ }^{2}$ School of Mechanical Engineering, Sharif University of Technology, Tehran, Iran \\ ${ }^{3}$ Faculty of Environment and Energy, Scienece and Research Branch, Islamic Azad University, Tehran, Iran \\ Correspondence: Alireza H. Kani, Energy Engineering Dep., Faculty of Environment and Energy, Scienece and \\ Research Branch, Islamic Azad University, Tehran, Iran. North Sattari Highway, Daneshgah Sq.. Tel: \\ 98-91-2303-2169. E-mail: alirezahkani@gmail.com
}

$\begin{array}{ll}\text { Received: July 7, 2013 } & \text { Accepted: August 6, 2013 } \quad \text { Online Published: August 26, } 2013 \\ \text { doi:10.5539/ijef.v5n9p148 } & \text { URL: http://dx.doi.org/10.5539/ijef.v5n9p148 }\end{array}$

\begin{abstract}
This paper attempt to estimate the natural gas demand function in Industry Sector of Iran for the period 1971 to 2009 using a regime-switching model entitled Smooth Transition Auto-regression model (STAR). To this end, explanatory variables such as value added of industry sector, real price of natural gas, real price of oil products, and real price of electricity are employed as variables influencing natural gas consumption in industry sector of Iran. The results show that natural gas demand in industry sector follows an LSTR1 model as a two-regime nonlinear model if real price of oil products is assumed as transition variable. The estimation results show that the slope parameter equals a high value of 10 and the threshold extreme value stands at 50.29 Rials per each liter of oil products consumed (Note 1). The results also indicate that in both regimes, value added of industry sector and real price of electricity have a positive and significant relation, and real price of natural gas has a reverse and significant relation with natural gas demand in industry sector. Further, real price of oil products does not have any significant relation with natural gas demand.
\end{abstract}

Keywords: natural gas demand, industry sector, STAR Model

\section{Introduction}

Natural gas is considered as one of the key energy resources for industry sector and production of electricity in most of the countries. In fact, due to the fact natural gas, in comparison with other fossil fuels, emits less amount of $\mathrm{CO} 2$, its utility has taken an incremental trend in recent years and has been called the "better energy source of 21st century" (Apergis \& Payne, 2010). That is the reason the global production level of natural gas has increased 1.7 times and US Energy Information Administration has predicted that this level will double by 2020 (Iman et al., 2004).

The subject of natural gas demand in industry sector of Iran is in some respects interesting. First, owning 15 percent of world's gas reserves, Iran is the second rich country in this respect. Second, the general policy of Iran's Energy Sector aims to replace other energy resources such as oil products with natural gas. To this end, the amount of natural gas consumed in industry sector has increased significantly from 1971 to 2009; the amount has increased from 3.34\% in 1971 to $61.61 \%$ in 2009 (Energy Balance Sheet, 2009). Finally, due to the significant subsidy granted by government till 2009 , natural gas has been supplied with a price lower than the global price. It is worth to note that, Iranian government has decided to remove the subsidy gradually. Therefore, evaluation of impact factors of natural gas demand in industry sector of Iran can be of much avail in regard with planning and policy-makings for this valuable energy carrier.

The literature on this subject covers two general spectrums of studies. One group of studies have dealt with natural gas demand function for residential sector or economy in general; among such studies, Balestra \& Nerlove (1966), Bloch (1979), Herbert (1987), Maddala et al. (1997), Shukla et al. (2009), Bernestein \& Madlener (2011), and Payne et al. (2011) can be mentioned. The other group has also studied gas demand function for residential sector or economy in general but their main effort has been focused on reducing the 
estimation error. Among such studies, Liu \& Lin (1991), Eltony (1996), Kaboudan \& Liu (2004), Aras \& Aras (2004), Forizanfar et al (2010) can be mentioned.

No major study has so far tried to estimate natural gas demand for industry sector. This may be due to the fact that natural gas plays a minor role in providing the energy for industry sector in most of the countries.

Despite the significance of natural gas share in energy provision for industry sector in Iran, only Azarbayjani et al. (2007) have estimated the natural gas demand function for industry sector in Iran using the Autoregressive Distributed Lag (ARDL). Their obtained results indicate that real price of natural gas and real price of electricity does not have any significant impact on gas consumption in industry sector and only value added of industry sector has a significant and positive impact on natural gas consumption. As natural gas demand in industry sector in Iran may follow a nonlinear and asymmetric pattern and since this issue has not been taken into consideration in Azarbayjani et al (2007) study, their obtained results may not be reliable and the issue must be re-studied. Moreover, many of studies such as Moral \& Vicens (2005), Bessec \& Fouquau (2008), and Joets \& Mignon (2012) have shown the presence of a nonlinear and asymmetric behavior between energy carriers and impact variables.

The present study aims to estimate gas demand function for industry sector in Iran using the Smooth Transition Autoregressive model (STAR). STAR Model is considered as one of the most significant regime switching models which is able to model the nonlinear relation between variables sequentially using transition function. The STAR model is not only able to determine the number and time of regime switches, but also the speed of transition from one regime to the other regime. Therefore, to the knowledge of authors of this paper, no study has yet been focused on natural gas demand in industrial sector in Iran using STAR.

With regard to the structure of the paper, chapter 2 discusses the methodology and chapter 3 presents the data and the experimental results. The conclusions are presented in chapter 4.

\section{Method}

\subsection{Methodology}

Considering the limitations imposed by linear models, many of studies have recommended nonlinear models for specification of nonlinear behavior in time series. This paper uses STAR model developed by Ter"asvirta \& Anderson (1992) and Ter"asvirta (1994 \& 1998) for modeling the nonlinear behavior of natural gas demand in industry sector. In contrast to Threshold Auto-regression (TAR) models which use indicator function for controlling regime-switching mechanism, STAR models make use of exponential and logistic function for this purpose. These models are appropriate for analysis of asymmetric cycles of variables and many studies have shown that these models fit regime-switching mechanism properly for evaluation of nonlinear dynamics of variables (Van Dijk \& Terävirta, 2002). In fact, STAR model is able to model the nonlinear relation between variables sequentially using transition variable and slope parameter. Smooth Transition Regression Models (Teräsvirta, 1994) are specified as a general regression equation as follows:

$$
y_{t}=\pi^{\prime} z_{t}+\theta^{\prime} z_{t} F\left(s_{t}, \gamma, c\right)+u_{t}
$$

Where $z_{t}$ is a vector including exogenous variables of the model, $\pi$ is the vector of linear parameters, $\theta$ is the vector of nonlinear parameters and $u_{t}$ is part of residuals which is assumed to be evenly and independently scattered with an average of 0 and constant variance $\left(u_{t} \approx i i d\left(0, \sigma^{2}\right)\right)$.

The transition function $F\left(s_{t}, \gamma, c\right)$ can also be specified logistically and exponentially by following equations:

$$
F\left(s_{t}, \gamma, c\right)=\left[\frac{1}{\left(1+\exp \left(-\gamma\left(s_{t}-c\right)\right)\right]}\right]
$$

Or,

$$
\mathrm{F}\left(s_{t}, \gamma, c\right)=\left[1-\exp \left(-\gamma\left(s_{t}-c\right)\right)^{2}\right]
$$

Equation 2 displays the logistic transition function and equation 3 shows the exponential transition function. In above transition functions, $s_{t}$ stands for transition variable; $\gamma$ is the slope parameter and $c$ is the threshold extreme or the point where the regime switch occurs. As Slope parameter $\gamma$, indicating the speed of transition from one regime to another, tends toward infinity, the SATR model turns into a 1TAR model; that is, if the transition variable is larger than threshold extreme $\left(s_{t}>c\right)$, transition function equals $1(\mathrm{~F}=1)$, in contrast, if $s_{t}<c$, then the value of transition function equals $0(\mathrm{~F}=0)$. Also, as slope parameter tends toward 0 , the SATR model turns into a linear model. 
The estimation process of STR model starts with selecting the dynamic process of model or the number of optimal lags, then determining whether there is a nonlinear relationship between the variables under study and then selecting the transition variable and the number of regime switching. The next step is estimation of selected STR model using Newton-Raphson algorithm and maximum likelihood estimation method. Some specification tests are carried out in the final step to assess the reliability of the obtained results.

Although linearity test of STAR model can be performed by null hypothesis $H_{0}: \gamma=0$ or $H_{0}: \theta=0$, as STAR model contains unidentified nuisance parameters within the context of null hypothesis, the test statistic of both above hypothesis are considered as substandard. To overcome this problem, Luukkonen (1998) recommended using Taylor approximation of transition function. To this end, the third order Taylor approximation of transition function $F\left(S_{t}, \gamma, c\right)$ is used in terms of parameter $\gamma$ at the point of $\gamma=0$. Thus, the regressive equation 1 can be rewritten as below:

$$
y_{t}=\pi^{\prime} z_{t}+\theta^{\prime} z_{t} \gamma F_{\gamma}\left(s_{t}, \gamma=0, c\right)+\theta^{\prime} z_{t} \gamma^{2} F_{\gamma \gamma}\left(s_{t}, \gamma=0, c\right)+\theta^{\prime} z_{t} \gamma^{3} F_{\gamma \gamma \gamma}\left(s_{t}, \gamma=0, c\right)+u_{t}
$$

Replacing $\gamma=0$ value and simplification of first to third order derivatives of the transition function would yield the following auxiliary regressions depending on whether the transition variable $s_{t}$ is included among $z_{t}$ variables or not:

If the transition variable $s_{t}$ is included among $z_{t}$ variables, then the simplified version of equation 4 is as below:

$$
y_{t}=\beta_{0}^{\prime} \tilde{z}_{t}+\beta_{1}^{\prime} \tilde{z}_{t} s_{t}+\beta_{1}^{\prime} \tilde{z}_{t} s^{2}{ }_{t}+\beta_{I}^{\prime} \tilde{z}_{t} s^{3}{ }_{t}+v_{l t}
$$

Where $z_{t}=\left(1, \tilde{z}_{t}\right)^{\prime}$.

If the transition variable $s_{t}$ is not included among $z_{t}$ variables, then the simplified version of equation 4 is as below:

$$
y_{t}=\beta_{0}^{\prime} z_{t}+\beta_{1}^{\prime} z_{t} s_{t}+\beta_{1}^{\prime} z_{t} s^{2}{ }_{t}+\beta_{1}^{\prime} z_{t} s^{3}{ }_{t}+v_{2 t}
$$

The null hypothesis of the linearity of the relationship between the dependent and explanatory variables in contrast to the alternative hypothesis, i.e. presence of nonlinear relationship between variables, can be conducted as the following coefficients test:

$$
H_{01}: \beta_{1}=\beta_{2}=\beta_{3}=0
$$

The statistic of the above test contains $\mathrm{F}$ distribution.

If the relation between variables is nonlinear, an appropriate nonlinear model must be selected. To select an appropriate model, three coefficients tests with the following null hypotheses are presented. The statistics of these tests contain $\mathrm{F}$ distribution.

$$
\begin{gathered}
H_{02}: \beta_{1}=0 \mid \beta_{2}=\beta_{3}=0 \\
H_{03}: \beta_{2}=0 \mid \beta_{3}=0 \\
H_{04}: \beta_{3}=0
\end{gathered}
$$

The statistics of above tests are shown as $F_{2}, F_{3}, F_{4}$ respectively. Rejection of $H_{03}$ indicates that the optimum model is either logistic STR with two regime switches (LSTR2) or an exponential STR (ESTR), one of which can be chosen by test of $H_{0}: c_{1}=c_{2}$ hypothesis. Rejection of the null hypothesis of this test signifies that LSTR2 is the optimum model. On the other hand, rejection of $H_{02}$ and $H_{04}$ hypotheses indicates that the optimum model is LSTAR with one regime switch (LSTAR1). To choose an appropriate transition variable among various candidates, a variable is chosen which is of the strongest $F$ variable in rejection of null hypotheses. As mentioned before, the selected nonlinear model is estimated based on Newton-Raphson algorithm.

After fitting of the nonlinear model, specification tests including uneven variance test, serial autocorrelation test, no remaining nonlinearity test, and parameters constancy test were run in different regimes on residuals yielded by this model to assess the capability of the nonlinear model to fit the behavior and nonlinear relation between the variables.

\subsection{Data}

Although many factors influence the natural gas demand in industry sector, some important factors such as value added of industry sector, price of natural gas, and price of other energy carriers such as oil products and electricity can theoretically be mentioned. Of course, selection of these variables follows the demand law; that is, 
selection of any commodity is subject to revenue, price of commodity, and price of rival commodities. Therefore, the above pattern can be specified in a linear equation as below:

$$
\operatorname{lgas}_{t}=\text { ly }_{t}+\text { lpgas }_{t}+\text { lpoil }_{t}+\text { lpelec }_{t}
$$

Where lpgas $_{t}$ is natural gas consumption in industry sector in million cubic meter, $l y_{t}$ is value added of industry sector as per fixed prices of 1999 in billion Rials, lpgas ${ }_{t}$ is real price of natural gas in industry sector in Rials/cubic meter, lpoil $l_{t}$ is the real price of oil products in industry sector in Rials/liter, and lpelec $_{t}$ is real price of electricity in industry sector in Rials/kilowatt-hour. It is worth to note that, all variables are used algorithmically and the period 1971 to 2009 is under study. The study also uses annual statistics.

\section{Results}

Before estimation of STAR model for natural gas demand in industry sector, it is necessary to determine the number of optimal lags for the used variables. As recommended by Pesaran and Smith (1998), Schwarz Bayesian Criterion (SBC), in comparison of other criteria, is of highest efficiency for samples with limited volume. Therefore, SBC is employed in this study for determining the number of optimal lags. Results indicate on lag for natural gas consumption variable and no lags for other variables. To select the transition variable, all variables existing in model include dependent variable lag, independent variable, and test case trend. Among above tested variables, the one with the highest probability of rejecting the null hypothesis of linearity will be chosen as the transition variable. It is also worth to note the proposed STAR model is selected by the transition variable as the optimum model for estimation of natural gas demand in industry. The results reflected in table 1 show that except transition variable of value added of industry sector (ly) which indicates a linear model, other tested transition variables strongly suggest the presence of a nonlinear relationship. Also, transition variable of lag of natural gas consumption in industry sector (lgas(1-)) of LSTR1 model, transition variable of natural gas price in industry sector (lpgas) of LSTR1 model, transition variable of oil products price in industry sector (lpoil) of LSTR1 model, transition variable of electricity price in industry sector (lpelec) of LSTR2 model and transition variable of trend of LSTR1 model are recommended. With regard to the fact that the least likelihood value of F statistic, which indicates the rejection of linearity null hypothesis in the strongest manner and relates to transition variable of lpoil, LSTR1 model and transition variable of oil products price in industry sector (lpoil) is selected.

Table 1. Linearity test, selection of transition variable and type of model

\begin{tabular}{cccccc}
\hline $\begin{array}{c}\text { Proposed } \\
\text { Model }\end{array}$ & $\begin{array}{c}\text { Likelihood of } \\
\text { Statistic F2 }\end{array}$ & $\begin{array}{c}\text { Likelihood of } \\
\text { Statistic F3 }\end{array}$ & $\begin{array}{c}\text { Likelihood of } \\
\text { Statistic F4 }\end{array}$ & $\begin{array}{c}\text { Likelihood of } \\
\text { Statistic F }\end{array}$ & $\begin{array}{c}\text { Transition } \\
\text { Variable }\end{array}$ \\
\hline LSTR1 & $1 / 4421 \mathrm{e}-02$ & $1 / 2367 \mathrm{e}-01$ & $2 / 8808 \mathrm{e}-01$ & $2 / 8148 \mathrm{e}-02$ & lgas $(-1)$ \\
Linear & $2 / 5914 \mathrm{e}-02$ & $1 / 9968 \mathrm{e}-02$ & - & - & ly \\
LSTR 1 & $3 / 4651 \mathrm{e}-02$ & $6 / 4982 \mathrm{e}-02$ & $2 / 0887 \mathrm{e}-01$ & $2 / 0565 \mathrm{e}-02$ & lpgas \\
LSTR 1 & $6 / 8052 \mathrm{e}-04$ & $2 / 9405 \mathrm{e}-02$ & $2 / 1733 \mathrm{e}-02$ & $1 / 0280 \mathrm{e}-04$ & lpoil \\
LSTR 2 & $5 / 2917 \mathrm{e}-02$ & $4 / 7295 \mathrm{e}-02$ & $4 / 4130 \mathrm{e}-01$ & $4 / 6223 \mathrm{e}-02$ & lpelec \\
LSTR 1 & $1 / 6784 \mathrm{e}-03$ & $1 / 7026 \mathrm{e}-01$ & $3 / 3830 \mathrm{e}-01$ & $1 / 8321 \mathrm{e}-02$ & Trend \\
\hline
\end{tabular}

In the next stage, natural gas demand function in industry sector is modeled using an LSTR1 model in which the price of oil products in industry sector is the transition variable. To this end, the initial threshold values of transition variable $[\mathrm{C}]$ and slope parameter $(\gamma)$ are chosen and then using these initial values and Newton-Rafson algorithm, the parameters of the model are estimated using Maximum Likelihood. The results are shown in tables $2 \& 3$. The estimation results show that oil products price variable in industry sector and also in both linear and nonlinear parts as well as the lag of natural gas consumption in the nonlinear part of the model are not significant. Of course, other variables affect natural gas demand in industry sector as much as 5 percent and at a significant level in both linear and nonlinear parts. 
Table 2. Estimation of LSTR1 Model (Linear part)

\begin{tabular}{cccc}
\hline Variable & Coefficient & Statistic t & Likelihood \\
\hline lgas $(-1)$ & 0.47 & 4.14 & 0.000 \\
ly & 0.67 & 3.66 & 0.001 \\
lpgas & -0.32 & -2.28 & 0.031 \\
lpoil & 0.09 & 0.52 & 0.60 \\
lpelec & 0.42 & 3.68 & 0.001 \\
Constant & -3.33 & -3.69 & 0.001 \\
\hline
\end{tabular}

Table 3. Estimation of LSTR1 Model (Nonlinear part)

\begin{tabular}{|c|c|c|c|}
\hline \multicolumn{4}{|c|}{ Estimation of the nonlinear part of the model } \\
\hline Variable & Coefficient & Statistic $\mathrm{t}$ & Likelihood \\
\hline $\operatorname{lgas}(-1)$ & 0.47 & 0.97 & 0.34 \\
\hline ly & 1.76 & 1.83 & 0.078 \\
\hline lpgas & -0.92 & -2.07 & 0.043 \\
\hline lpoil & 3.72 & 1.42 & 0.16 \\
\hline lpelec & 2.11 & 3.17 & 0.005 \\
\hline Constant & -42.45 & -2.10 & 0.046 \\
\hline Threshold Extreme (C) & 3.91 & 74.75 & 0.000 \\
\hline Slope Parameter $\gamma$ & 10.69 & 3.24 & 0.003 \\
\hline
\end{tabular}

As shown in table 3, the slope parameter, which stands for the speed of transition from one regime to another, is estimated to be 10.69 which signify the rapid transition of regimes. Threshold extreme is estimated as being 3.91 logarithmically and its anti-logarithm equals 50.29 Rials/liter for real price of oil products indicating that if, considering the transition speed determined by the slope parameter, the real price is higher than 50.29 Rials/liter, then we enter the second regime. As illustrated, the model is of two different extreme regimes, one belonging to the condition when transition variable value (lpoil) is smaller than the extreme threshold 3.91 and the second regime belongs to the condition when transition variable value (lpoil) is larger than the extreme threshold 3.91. Thus, the transition function $F\left(S_{t}, \gamma, c\right)$ is specified as below for the two extreme states, $\mathrm{G}=0$ and $\mathrm{G}=1$ :

The first extreme regime $\mathrm{G}=0$ :

$$
\text { lgas }=-3.33+0.47 \operatorname{lgas}(-1)+0.67 l_{y}-0.32 \text { lpgas }+0.09 \text { lpoil }+0.42 \text { lpelec }
$$

The second extreme regime $\mathrm{G}=1$

$$
\text { lgas }=-45.78+0.94 \operatorname{lgas}(-1)+2.43 l_{y}-1.24 \text { lpgas }+3.81 \text { lpoil }+2.53 \text { lpelec }
$$

The results of both above extreme regimes show that the value added of industry sector in both extreme regimes has a positive impact on natural gas which is according to theoretic expectations. That is, along with increase in the value added of industry sector, demand natural gas as a production input increases. The impact level is highest in the second extreme regime. In fact, the impact level is 0.67 and 2.43 in the first and second extreme regimes respectively. The real price of natural gas has an inverse relation its demand in both extreme regimes which conforms to theoretic expectation of demand laws. That is, increasing the price of this energy carrier will lead to an increase in its demand. It is worth to note that the coefficient of natural gas price is larger and of more impact in the second extreme regime. The price coefficient in the first and second regime is -0.32 and -1.24 respectively. Although the real price of oil products has a positive impact on natural gas demand, it is not significant. Real price of electricity coefficient in industry sector and first \& second extreme regimes is $0.42 \&$ 2.53; thus conforming to the theoretic expectations, it has a positive and significant impact on natural gas demand in industry sector. Demand for other energy carriers such as natural gas as a production input was expected to rise as the price of electricity increased. This results from the substitution characteristic of energy carriers. Finally, the lag in natural gas consumption in the first extreme regime has a significant impact on natural gas demand. Natural gas demand in industry sector thus seems to be affected by last year lag. It is worth to note that the provided coefficients are extreme, and the value of transition variable and slope parameter is between the two extreme regimes in reality.

The diagrammatic view of threshold extreme of 3.91with transition variable, i.e. real price of oil products in industry, can display the difference between the two extreme regimes more effectively (Figure 1). As illustrated in the diagram, the second extreme regime, that is the real price of oil products which is more than 3.91 (anti 
algorithm of 50.29), relates to the years before 1980 and the first extreme regime relates to the years after 1980 . This is mainly due to the fact that after the Islamic revolution of 1978 in Iran, government granted a large amount of subsidy to energy carriers, and as a result natural gas was supplied with a price much lower than the global price. Also, as the nominal price of oil products has increased much less than the consumer price indicator, the real price of oil products has followed a downward trend during the period under question.

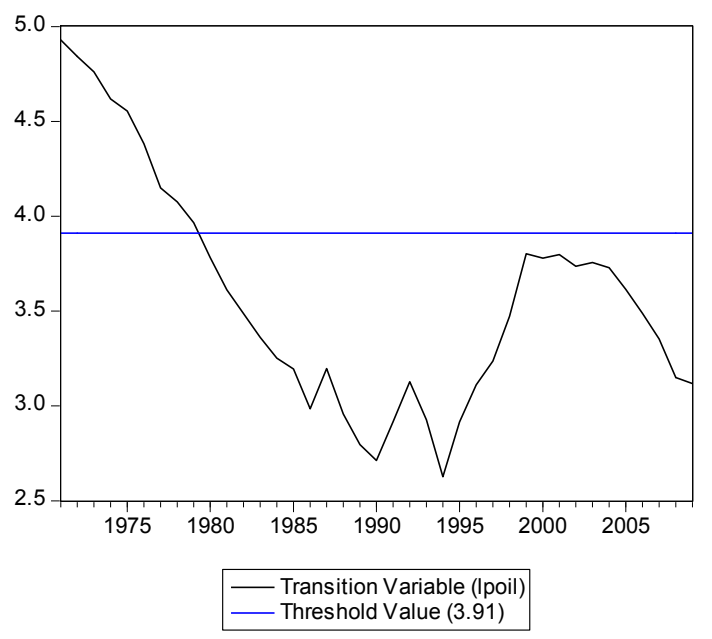

Figure 1. The trend of transition variable of real price of oil products and threshold value of 3.91

Tables 4 and 5 report the results of specification tests of uneven variance test, serial autocorrelation test, no remaining nonlinearity test, and parameters constancy test. As shown, there is no correlation and uneven variance error in LSTR1 model. The no remaining nonlinearity test also shows that LSTR1 model specifies all existing nonlinear relations in the model. The results of Parameters constancy test in different regimes also shows that the null hypothesis of test based on the constancy of coefficients and parameters of the mode is rejected in both regimes and the result that the coefficients of explanatory variables are different in the two regimes and have asymmetric impacts on dependent variable, i.e. natural gas consumption, is confirmed. Therefore, according to the results of the estimation model and specification tests, LSTR1 proves to be an appropriate model for identifying the behavior of natural gas demand in industry sector of Iran. The results yielded by the model prove to be reliable.

Table 4. Auto correlation test

\begin{tabular}{ccccc}
\hline \multicolumn{5}{c}{ Testing for Auto Correlation } \\
\hline p-value & df2 & df1 & F-value & lag \\
0.68 & 22 & 1 & 0.17 & 1 \\
0.67 & 20 & 2 & 0.39 & 2 \\
0.81 & 18 & 3 & 0.31 & 3 \\
0.94 & 16 & 4 & 0.18 & 4 \\
\hline
\end{tabular}

Table 5. Results of specification tests

\begin{tabular}{ccc}
\hline Test & F-value & P-value \\
\hline ARCH LM-test & 0.32 & 0.94 \\
No remaining nonlinearity test & - & 0.57 \\
Parameters constancy test & 2.98 & 0.038 \\
\hline
\end{tabular}

\section{Discussion}

This paper studied the natural gas demand function in industry sector of Iran using STAR model as one of the 
most significant regime-switching models. To this end, various variables including value added of industry sector, real price of natural gas, real price of oil products and real price of electricity have been employed as factors impacting natural gas consumption in industry sector of Iran for the period extending from 1971 to 2009.

The estimation results strongly indicate that there is a nonlinear relation between the variables under study. To this end, real price of oil products was chosen as the best transition variable and LSTR1 model with two extreme regimes was recommended for the specification of the nonlinear model of natural gas demand function in industry sector. The slope parameter, as the indicator of speed of transition from one regime to another, was estimated to be 10.69 and the value of extreme threshold, where the regime switching occurs, was estimated to be 50.29 Rials/liter of real price of oil products by LSTR1 model. The coefficient of value-added of industry sector variable was positive in both regimes; however, the impact level was different in the two extreme regimes, being 0.67 and 2.43 highest in the first and second regimes respectively. Real price of natural gas also has an inverse and significant relation with natural gas demand in industry sector in both regimes, being -0.32 in the first regime and -1.24 in the second. The coefficient of real price of electricity stood at 0.42 in the first regime and 2.53 in the second. Price of oil products variable does not have a significant impact on natural gas demand in industry sector.

It can thus be concluded that electricity and natural gas, as production inputs, can be substituted with one another; that is, increasing the price of electricity, the demand for natural gas also increases accordingly. Also, revenue increase in industry sector has a considerable impact on the increase of natural gas demand in this sector.

\section{References}

Apergis, N., \& Payne, J. E. (2010). Natural gas consumption and economic growth: A panel investigation of 67 countries. Applied Energy, 87, 2759-2763. http://dx.doi.org/10.1016/j.apenergy.2010.01.002

Aras, H., \& Aras, N. (2004). Forecasting residential natural gas demand. Energy Sources, 26(5), 463-72. http://dx.doi.org/10.1080/00908310490429740

Azarbayjani, K., Sharifi, A., \& Shojaei, A. (2008). Estimating the natural gas demand function in industrial sector of Iran. Tosei \& Sarmaye, 1, 47-70.

Balestra, P., \& Nerlove, M. (1966). Pooling cross section and time series data in the estimation of a dynamic model: The demand for natural gas. Econometrical, 34, 585-612. http://dx.doi.org/10.2307/1909771

Bernestein, R., \& Madlener, R. (2011). Residential natural gas demand elasticities in OECD countries: An ARDL Bound testing approach. working paper, E. ON Energy Research Center.

Bessec, M., \& Fouquau, J. (2008). The nonlinear link between electricity consumption and temperature in Europe: A threshold panel approach. Energy Economics, 30(5), 2705-2721. http://dx.doi.org/10.1016/j.eneco.2008.02.003

Bloch, F. E. (1979). Residential demand for natural gas. Journal of Urban Economics, 7, 371-83. http://dx.doi.org/10.1016/0094-1190(80)90008-X

Eltony, M. N. (1996). Demand for natural gas in Kuwait: An empirical analysis using two econometric models. Int. $\quad J . \quad$ Energy Res., http://dx.doi.org/10.1002/(SICI)1099-114X(199611)20:11<957::AID-ER206>3.0.CO;2-N

Forouzanfar, F., Doustmohammadi, A., Bagher, M. M., \& Hasanzadeh, S. (2010). Modeling and estimation of the natural gas consumption for residential and commercial sectors in Iran. Applied Energy, 87, 268-274. http://dx.doi.org/10.1016/j.apenergy.2009.07.008

Herbert, J. H. (1987). Data matters: Specification and estimation of natural gas demand per customer in the Northeastern United States. Computation Statistics and Data Analysis, 5, 67-78. http://dx.doi.org/10.1016/0167-9473(87)90009-0

Iman, A., Startzman, R. A., \& Barrufet, M. A. (2004). Multi-cyclic Hubbert model shows global conventional gas output peaking in 2019. Oil Gas J, 16(August), 20-8.

Joets, M., \& Mignon, V. (2012). On the link between forward energy price: A nonlinear panel cointegration approach. Energy Economics, 34(4), 1170-1175. http://dx.doi.org/10.1016/j.eneco.2011.10.019

Kaboudan, M. A., \& Liu, Q. W. (2004). Forecasting quarterly US demand for natural gas. E-J: Inform Technol Econ Manage, 2(1), 1-14.

Liu, L. M., \& Lin, M. W. (1991). Forecasting residential consumption of natural gas using monthly and quarterly time series. Int J Forecast, 7(1), 3-16. http://dx.doi.org/10.1016/0169-2070(91)90028-T 
Luukkonen, R., Saikkonen, P., \& Teräsvirta, T. (1998). Testing linearity against smooth transition autoregressive models. Biometrika, 75, 491-499. http://dx.doi.org/10.1093/biomet/75.3.491

Maddala, G. S., Trost, R. P., Li, H., \& Joutz, F. (1997). Estimation of short- run and long-run elasticities of energy demand from panel data using shrinkage estimators. Journal of Business \& Economic Statistics, 15, 90-100.

Moral, C. J., \& Vicens, O. J. (2005). Modeling the nonlinear response of Spanish electricity demand to temperature variations. Energy Economics, 27, 477-494. http://dx.doi.org/10.1016/j.eneco.2005.01.003

Payne, J. E., Loomis, D., \& Wilson, R. (2011). Residential natural gas demand in Illinois: Evidence from the ARDL bound testing approach. Journal of Regional Analysis \& Policy, 41(2), 138-147.

Pesaran, M. H., \& Smith, R. P. (1998). Structural analysis of cointegration VARS. Journal of Economic Surveys, 12(5), 471-505. http://dx.doi.org/10.1111/1467-6419.00065

Shukla, P. R., Dhar, S., Victor, D. G., \& Jackson, M. (2009). Assessment of demand for natural gas from the electricity sector in India. Energy Policy, 37(9), 3520-3534. http://dx.doi.org/10.1016/j.enpol.2009.03.067

Teräsvirta, T. (1998). Modeling economic relationships with smooth transition regressions. In A. Ullah, \& D. E. Giles (Eds.), Handbook of Applied Economic Statistics (pp. 507-552). Dekker, New York.

Teräsvirta, T., \& Anderson, H. (1992). Characterizing nonlinearities in business cycles using smooth transition autoregressive models. Journal of Applied Econometrics, 7, 119-136. http://dx.doi.org/10.1002/jae.3950070509

Terävirta, T. (1994). Specification, estimation, and evaluation of smooth transition autoregressive models. Journal of the American Statistical Association, 89, 208-218.

Note

Note 1. 1 USD = 24770 Rials (Aug. 2013).

\section{Copyrights}

Copyright for this article is retained by the author(s), with first publication rights granted to the journal.

This is an open-access article distributed under the terms and conditions of the Creative Commons Attribution license (http://creativecommons.org/licenses/by/3.0/). 